\title{
Mechanical Properties of the CMS Conductor
}

\author{
Benoit Curé, Bertrand Blau, Alain Hervé, Pierluigi Riboni, Sandra S. Tavares, and Stefano Sgobba
}

\begin{abstract}
CMS (Compact Muon Solenoid) is a general-purpose detector designed to run at the highest luminosity at the CERN Large Hadron Collider (LHC). Its distinctive features include a $4 \mathrm{~T}$ superconducting solenoid with $6 \mathrm{~m}$ diameter by $12.5 \mathrm{~m}$ long free bore, enclosed inside a 10000 ton return yoke. The magnetic field is achieved by a 4-layer superconducting solenoid made of a high purity aluminum (HPA) stabilized Rutherford type superconductor. The magnet is operated at $4.5 \mathrm{~K}$, with a nominal current of $20 \mathrm{kA}$, for a total stored magnetic energy of $2.7 \mathrm{GJ}$. Due to the high magnetic forces at nominal field inside the winding pack, the structural component is the conductor itself to get a self-supporting winding structure. The mechanical reinforcement is made from aluminum alloy directly welded to the superconductor by Electron Beam (EB) welding technology before the winding operation. The external support cylinders also take part to the mechanical integrity.

At each step of fabrication of the CMS conductor, the mechanical properties of the components and bonding between them are measured by destructive testing on short samples, in complement of continuous monitoring during production. This paper presents the results of the superconducting cable to pure aluminum shear testing, the tensile testing of the EN AW 6082 aluminum reinforcement, the insert to reinforcement shear testing, and the tensile testing of the full conductor before and after heat treatment induced during coil curing. Possible influence of the EB welding on the mechanical properties of the final conductor is investigated. Residual Resistivity Ratio (RRR) measurements of the HPA stabilizer are presented. Mechanical properties and equivalent RRR of the CMS conductor are presented for comparison with conductors of other geometry.
\end{abstract}

Index Terms-Aluminum alloys, CMS superconducting magnet, conductors, mechanical properties.

\section{INTRODUCTION}

$\mathbf{T}$ HE CMS experiment (Compact Muon Solenoid) is a general-purpose proton-proton detector designed to run at the highest luminosity at the LHC [1]. Distinctive features of the CMS detector include a high-magnetic-field solenoid (4 T) coupled with a multilayer muon system, a fully active scintillatingcrystal electromagnetic calorimeter, a tile hadronic calorimeter, and a powerful inner tracking system.

The CMS magnet main features are a $12.5 \mathrm{~m}$ magnetic length, with a $6.36 \mathrm{~m}$ diameter aperture, indirectly cooled down and operated at $4.5 \mathrm{~K}$. The magnet is built by winding five modules

Manuscript received October 21, 2003.

B. Curé, A. Hervé, S. S. Tavares, and S. Sgobba are with CERN, 1211 Geneva 23, Switzerland (e-mail: benoit.cure@ cern.ch).

B. Blau was with Swiss Federal Institute of Technology, 8093 Zürich, Switzerland. He is now with the Paul Scherrer Institute, 5232 Villigen PSI, Switzerland.

P. Riboni is with the Swiss Federal Institute of Technology, 8093 Zürich, Switzerland.

Digital Object Identifier 10.1109/TASC.2004.829712
TABLE I

CMS CONDUCTOR MAIN PARAMETERS

\begin{tabular}{lr}
\hline \hline Nominal current & $20 \mathrm{kA}$ \\
Superconducting strand type & NbTi- Cu stabilized \\
Strand Cu/SC ratio & 1.1 \\
Number of strands & 32 \\
Strand diameter & $1.28 \mathrm{~mm}$ \\
Rutherford cable cross section & $20.68 \mathrm{~mm} \times 2.34 \mathrm{~mm}$ \\
Insert cross section & $30 \mathrm{~mm} \times 21.6 \mathrm{~mm}$ \\
High Purity Aluminum stabilizer & $\mathrm{Al} 99.998 \%$ \\
RRR aluminum at 0 T, annealed & $>1500$ \\
Reinforcement material & $\mathrm{EN} \mathrm{AW-6082}$ \\
Conductor cross section & $64 \mathrm{~mm} \times 21.6 \mathrm{~mm}$ \\
Quantity produced & 21 lengths $\times 2600 \mathrm{~m}$ \\
\hline \hline
\end{tabular}

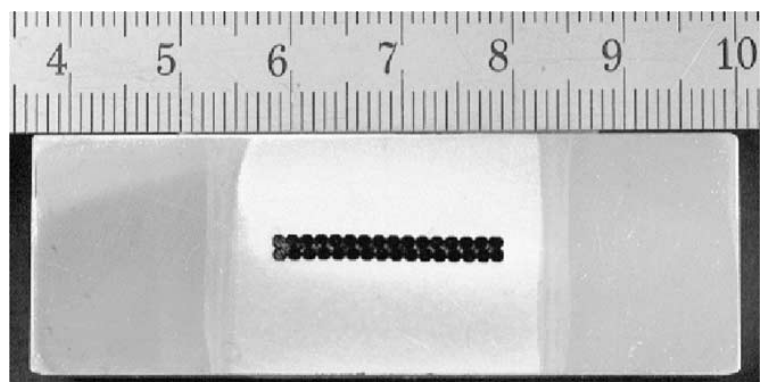

Fig. 1. Cross-section of the CMS conductor.

with four layers of reinforced superconductor, inside a $50 \mathrm{~mm}$ thick external cylinder [2]. The $20 \mathrm{kA}$ superconductor consists of a superconducting Rutherford type cable stabilized with High Purity Aluminum (HPA), and mechanically reinforced with two continuous sections of aluminum alloy [3] welded by Electron Beam (EB) technology [4]. Continuous EB welding was developed to produce $2.6 \mathrm{~km}$ conductor unit lengths [5], with dedicated ultrasonic on-line quality monitoring [6]. The main characteristics of the conductor are summarized in Table I. The cross-section of the conductor is presented in Fig. 1.

From the mechanical analysis [7], the hoop strain inside the winding is $0.15 \%$. The maximal hoop stress in the wound conductor is equivalent to a maximal tensile force on the conductor equal to $130 \mathrm{kN}$ or $94 \mathrm{MPa}$ on the total conductor cross-sectional area. In addition, the reinforced conductor must also support an axial pressure of $147 \mathrm{MN}$. The maximal shear stress at the interface between superconducting cable and HPA stabilizer is $11 \mathrm{MPa}$, and the maximal shear stress at the interface between reinforcement and HPA is $8 \mathrm{MPa}$, according to [7]. Previous characterizations of the reinforcement material [8] indicated a mechanical strength with comfortable margins. 


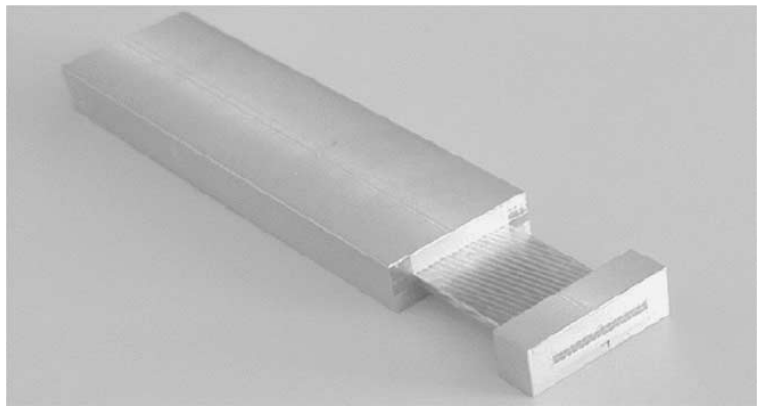

Fig. 2. Pull-out sample.

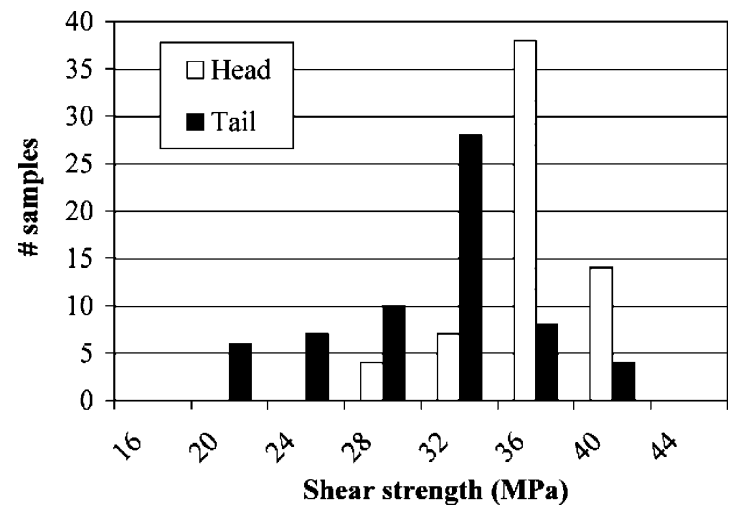

Fig. 3. HPA stabilizer-superconducting cable bonding shear strength at RT; 3 samples were measured at both head and tail of each insert.

\section{Mechanical Testing of Conductor COMPONENTS AND BONDING}

\section{A. Bonding of HPA Stabilizer to Superconducting Cable}

The Rutherford type cable is embedded inside a HPA matrix acting as the electrical and thermal stabilizer, to form the so-called insert. Unit lengths of $2600 \mathrm{~m}$ were produced by the co-extrusion process on a 3800-ton aluminum press [3]. The bonding between HPA stabilizer and superconducting cable was measured by a technique developed for previous aluminum stabilized conductors [9], using pull-out samples, as shown in Fig. 2. From the mechanical analysis [7], the bonding was specified at a minimum value of $20 \mathrm{MPa}$ at room temperature (RT), which includes a safety factor on the maximum computed shear stresses at $4.2 \mathrm{~K}$. The measurements on samples taken at the head and tail of each insert length are summarized on Fig. 3 for the total production of 21 insert units, including the length used for the prototype coil [1]. At RT, the shear stress at head is $38.0 \pm 3.2 \mathrm{MPa}$, and the shear stress at tail is $32.4 \pm 5.2 \mathrm{MPa}$, with a minimum measured shear stress value equal to $21 \mathrm{MPa}$.

Tests done on samples extracted from one conductor after the EB welding operation confirmed that no degradation of the bonding occurs due to the welding: the shear stress at head is $39.7 \pm 2.6 \mathrm{MPa}$, and the shear stress at tail is $35.5 \pm 2.4 \mathrm{MPa}$.

\section{B. Tensile Testing of EN AW-6082 Reinforcement}

The EN AW-6082 reinforcement sections are produced by continuous billet on billet extrusion process, with a pause ("stop over") during the introduction a new billet inside the press. The two EN AW-6082 aluminum alloy sections are EB welded to the

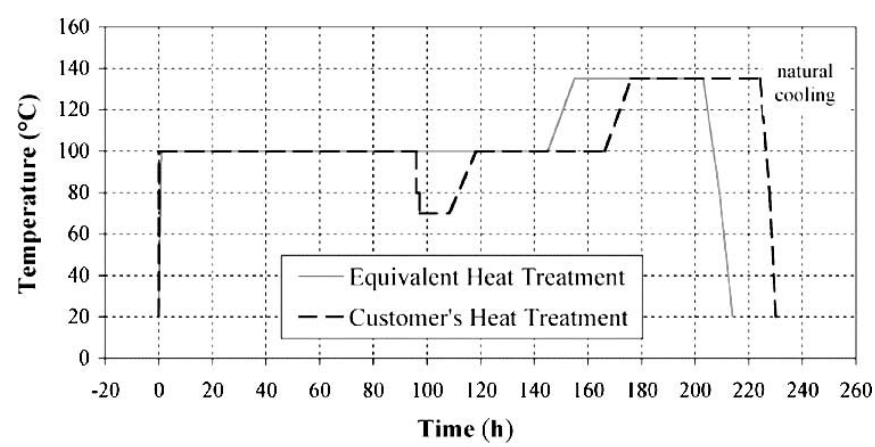

Fig. 4. Equivalent and customer's heat treatments.

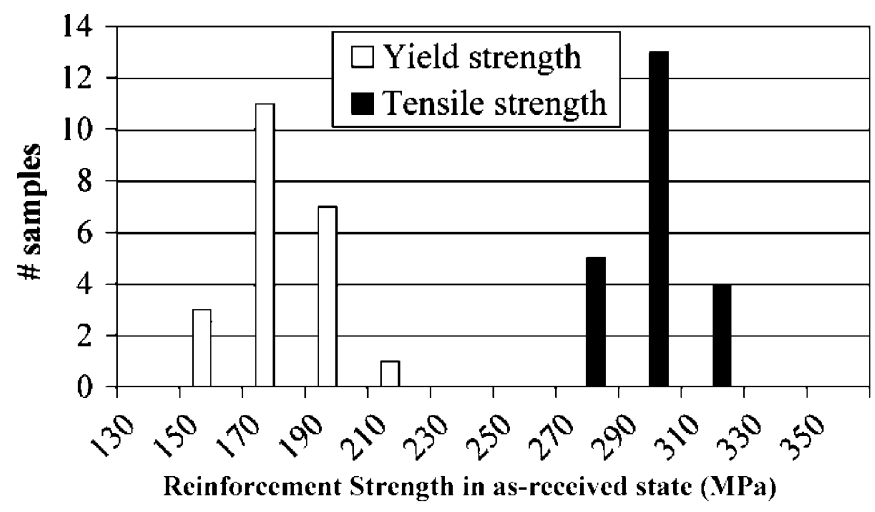

Fig. 5. EN AW-6082 minimum mechanical strength at RT in as-received state.

insert in the as-received state corresponding to the underaged and stabilized temper T51 [8]. The peak-aged properties of the reinforcement alloy are obtained during the curing cycle of the magnet coil itself, performed after winding of the conductor and corresponding to the impregnation heat treatment. This thermal treatment called customer's heat treatment has slightly evolved with respect to [10]. An equivalent heat treatment has been applied on the test specimens. The thermal cycles are described on Fig. 4.

The mechanical properties of each produced EN AW-6082 reinforcement batch have been measured in the as-received state at RT on samples taken around the stop over region [8]. Results for the 22 produced batches are presented in Fig. 5. The average yield strength is equal to $187 \pm 11 \mathrm{MPa}$, and the average tensile strength is $316 \pm 13 \mathrm{MPa}$. Table II presents the average tensile properties measured in the as-received state and after the customer's heat treatment at RT and at $4.2 \mathrm{~K}$, on samples extracted around the stop-over region [8].

\section{Bonding of Reinforcement to HPA Stabilizer}

In order to assess the bonding between the insert and the reinforcement, cylindrical specimen $\varnothing 21.5 \mathrm{~mm}$ were machined perpendicular to the conductor axis, according to the sketch given in Fig. 6. Shear tests at RT were performed with dedicated clamps. The minimum shear strength value was specified at $30 \mathrm{MPa}$ at RT, based on [7]. The measurements done on 16 conductor unit lengths are summarized in Fig. 7, where values at head and tail of each welded conductor are given. The values correspond to the maximum shear stress before rupture. At RT, 
TABLE II

SUMMARY OF THE MEASURED (MINIMUM SPECIFIED/EXPECTED) TENSILE PROPERTIES OF EN AW-6082 CONDUCTOR REINFORCEMENT

\begin{tabular}{lccc}
\hline \hline & $\begin{array}{c}\text { Yield Strength } \\
(\mathrm{MPa})\end{array}$ & $\begin{array}{c}\text { Tensile Strength } \\
(\mathrm{MPa})\end{array}$ & $\begin{array}{c}\text { Elongation } \\
(\%)\end{array}$ \\
\hline $\begin{array}{l}\text { As-received state, } \\
\text { at RT }\end{array}$ & $187(150)$ & $316(250)$ & $23(15)$ \\
$\begin{array}{l}\text { After customer's heat } \\
\text { treatment, at RT }\end{array}$ & $313(175)$ & $392(280)$ & $18.5(15)$ \\
$\begin{array}{l}\text { After customer's heat } \\
\text { treatment, at 4.2K }\end{array}$ & $428(225)$ & $687(550)$ & $18.2(15)$ \\
\hline \hline
\end{tabular}

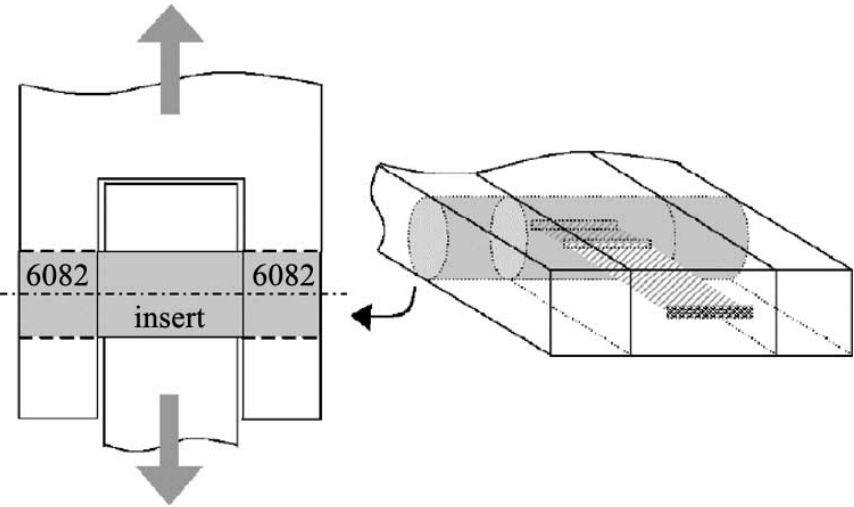

Fig. 6. Sketch of experimental setup used for reinforcement-insert bonding shear testing.

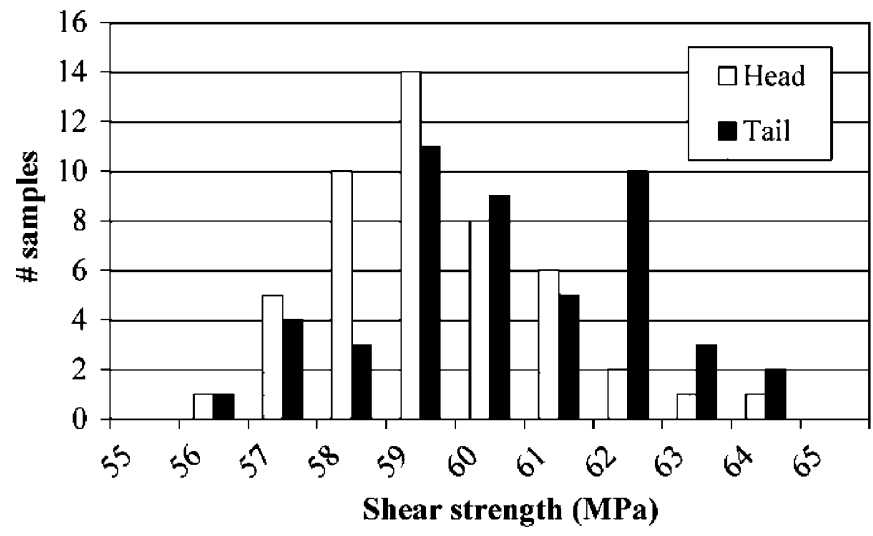

Fig. 7. EN AW-6082 reinforcement-insert bonding shear strength at RT; 3 samples were measured at both head and tail of each conductor.

the shear strength at head is $59.3 \pm 1.6 \mathrm{MPa}$, and the shear strength at tail is $60 \pm 1.9 \mathrm{MPa}$.

\section{Full Conductor Tensile Testing}

Tensile tests at RT were performed at the Swiss Federal Laboratories for Materials Testing and Research (EMPA), on a $500 \mathrm{kN}$ pulling machine. The sample thickness was reduced from $21.6 \mathrm{~mm}$ to $17.6 \mathrm{~mm}$ to keep the rupture out of the clamped areas. The cross section ratio of the cable in the specimen, expressed in percent of the insert cross-section, is $1.7 \%$ higher compared with real dimensions. Therefore the influence of the change in thickness on the mechanical properties is negligible. In order to quantify the effect of the customer's heat treatment on the conductor mechanical properties, tensile
TABLE III

Summary of the Measured Tensile Properties of FULL CONDUCTOR AT RT

\begin{tabular}{lcccc}
\hline \hline & Sample \# & $\begin{array}{c}\text { Yield Strength } \\
(\mathrm{MPa})\end{array}$ & $\begin{array}{c}\text { Tensile Strength } \\
(\mathrm{MPa})\end{array}$ & $\begin{array}{c}\text { Elongation } \\
(\%)\end{array}$ \\
\hline $\begin{array}{l}\text { Before } \\
\text { customer's heat } \\
\text { treatment }\end{array}$ & 1 & 130 & 214 & 20.0 \\
\hline $\begin{array}{l}\text { After customer's } \\
\text { heat treatment }\end{array}$ & 3 & 130 & 214 & 20.3 \\
\hline \hline
\end{tabular}

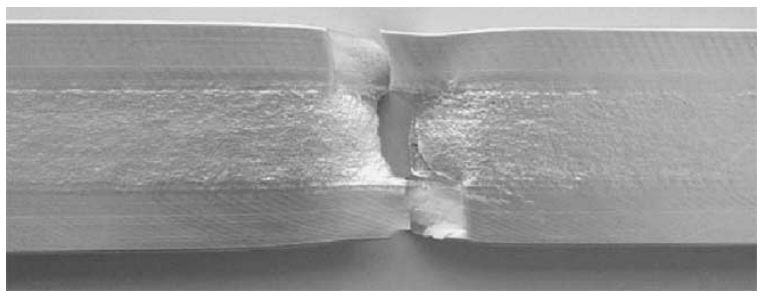

Fig. 8. Broken specimen view.

tests were carried out on two heat-treated specimens, with the thermal cycle given in Fig. 4. The results of the tests are given in Table III. Rupture surfaces in the reinforcements and in pure aluminum are typical of ductile fracture. One example of broken specimen is presented in Fig. 8. The HPA stabilizer is fully in the plastic domain at rupture.

\section{CONDUCtor Properties at $4.2 \mathrm{~K}$}

Knowing the mechanical properties measured and given in previous sections for the EN AW-6082 reinforcement and for the full conductor, it is possible to estimate the mechanical properties of the conductor at $4.2 \mathrm{~K}$, taking into account possible influence of the weld. Considering the temperature distribution given in [4] inside the conductor and its components during the continuous EB welding process, the heat affected zone effect is negligible outside the weld seam.

\section{A. Influence of the Electron Beam Welding}

The energy deposition during the EB welding process is localized to a narrow melted zone. The average weld seam width is $2.2 \mathrm{~mm}$ and the distance between the super-conducting cable and the weld seam is $3.4 \mathrm{~mm}$ [5]. The weld seam is distributed in the reinforcement and the insert, typically $1 \mathrm{~mm}$ penetration in the reinforcement and $1.2 \mathrm{~mm}$ penetration in the insert, from dimensions given in Table I. Two cases can be considered for calculation; either the reinforcement cross-section is diminished by the amount of the weld seam penetration and the weld is behaving like pure aluminum, or the nominal dimensions as given in Table I are used.

\section{B. Estimate of Mechanical Characteristics}

The equivalent stress $\sigma_{\mathrm{c}}$ acting on the full conductor can be calculated by the following relationship:

$$
\sigma_{c} S_{c}=\sum_{i} \sigma_{i} S_{i}=\sigma_{\text {insert }} S_{\text {insert }}+\sigma_{6082} S_{6082}
$$




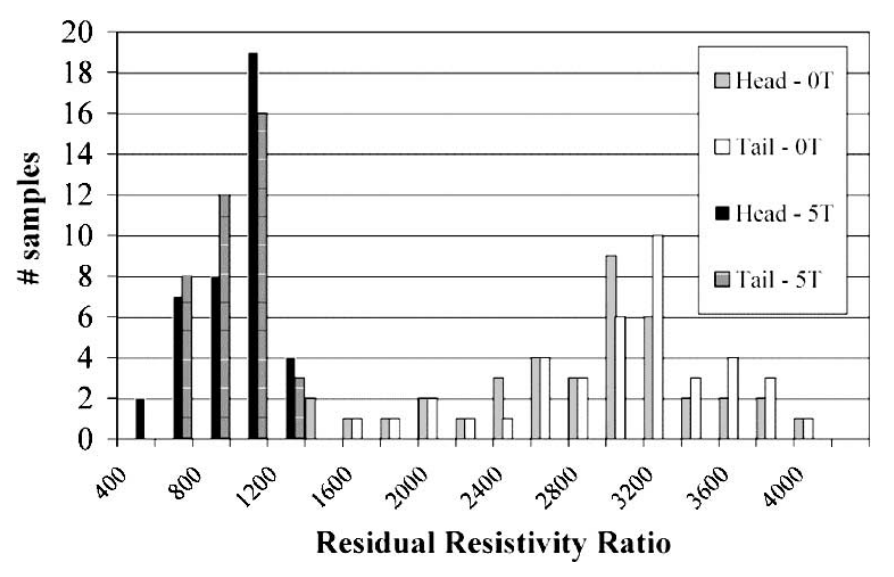

Fig. 9. HPA stabilizer RRR measurements on CMS inserts at $0 \mathrm{~T}$ and $5 \mathrm{~T}$.

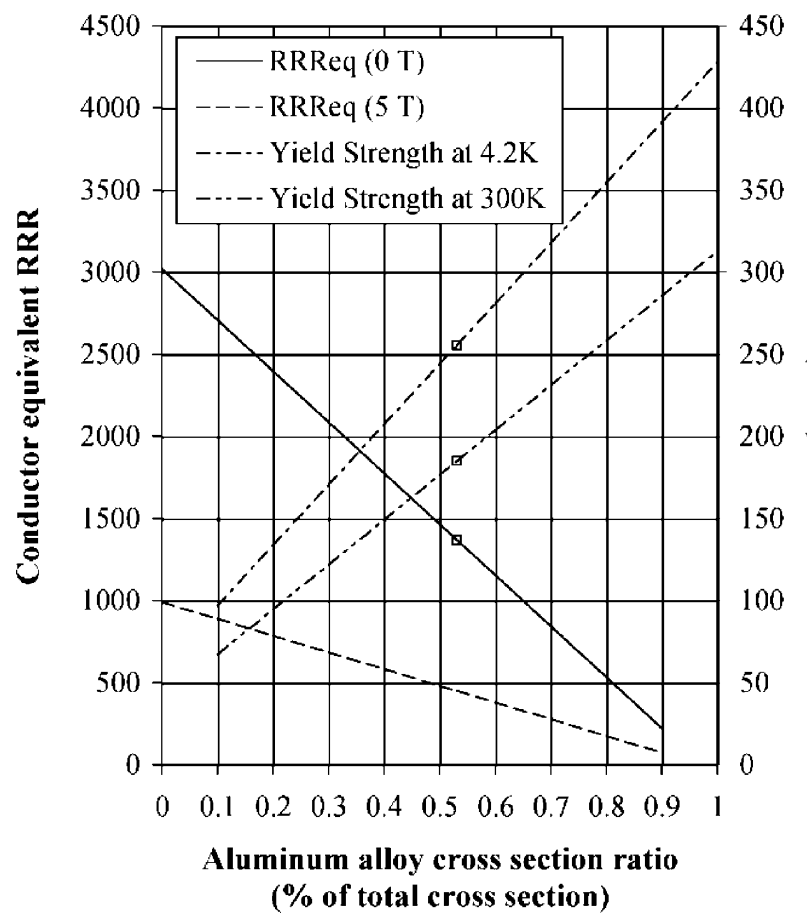

Fig. 10. CMS conductor equivalent RRR and yield strength vs aluminum alloy reinforcement cross section.

where $\sigma_{\text {insert }}$ and $\sigma_{6082}$ are respectively the stress in the insert and in the reinforcement, $S_{\text {insert }}$ and $S_{6082}$ are respectively the cross sectional area of the insert and the reinforcement.

The participation of the insert to the mechanical strength of the conductor cannot be neglected, as the cable reinforces the insert. Using (1) neglecting the insert is incompatible with measurements at RT given in Sections II and III.

Considering the yield (resp. tensile) strength of the insert at $4.2 \mathrm{~K}$ is superior to the yield (resp. tensile) strength at $300 \mathrm{~K}$, then, using $\sigma_{\text {insert }}$ at $300 \mathrm{~K}$ calculated from (1) at $0.2 \%$ yielding (resp. rupture) of the full conductor, the minimum yield (resp. tensile) strength value of the full conductor at $4.2 \mathrm{~K}$ can be calculated. At $4.2 \mathrm{~K}$, following the customer's heat treatment, the calculations give a conductor yield strength equal to $258 \mathrm{MPa}$, and a tensile strength of $406 \mathrm{MPa}$.

The difference in the results between the two cases described in the previous paragraph is less than $2.8 \%$.

\section{Residual Resistivity Ratio (RRR) of HPA Stabilizer}

The RRR is mostly influenced by the co-extrusion of the insert. The RRR of HPA billets in the as-received state was 3683 \pm 569 at $0 \mathrm{~T}$. After co-extrusion, the RRR of samples extracted from the inserts are $3020 \pm 606$ at $0 \mathrm{~T}$ and $989 \pm 184$ at $5 \mathrm{~T}$. This indicates that the RRR at zero field at $4.2 \mathrm{~K}$ stays above 950 following dynamic stress loading, according to [11]. Results for all the insert production is given in Fig. 9. The diffusion of impurities in HPA stabilizer can be neglected during the EB welding process. Therefore, to the first approximation, no degradation of the RRR is expected apart from the pure aluminum in the weld seam.

\section{DISCUSSION AND CONCLUSION}

As the reinforcement and the HPA are electrically in parallel, an equivalent Residual Resistivity Ratio $\left(\mathrm{RRR}_{\text {eq }}\right)$ can be calculated for the full conductor. The reinforcement resistivity is higher by a factor 1000 compared to the HPA at $5 \mathrm{~T}$ and at $4.2 \mathrm{~K}$, consequently the influence of the reinforcement resistivity on $\mathrm{RRR}_{\mathrm{eq}}$ is lower than $1 \%$, so the following simplified relationship is obtained:

$$
R R R_{e q}=(1-r) R R R_{H P A}
$$

where $r$ is the aluminum alloy cross-sectional ratio expressed in percent of the total conductor cross section.

From (1) and (2), both the yield strength and $R_{R R}$ eq can be represented on one graph, given in Fig. 10, For the CMS conductor, the ratio is $r=53 \%$, the corresponding data points are indicated in Fig. 10. The HPA stabilizer RRR and the reinforcement yield strength are obtained from this graph respectively for $r=0 \%$ and $r=100 \%$. This graph can be used as a reference when comparing conductors of other geometry with the CMS conductor.

\section{REFERENCES}

[1] A. Herve et al., Status of the Construction of the CMS Superconducting Magnet at LHC.

[2] P. Fabbricatore et al., The Construction of the Modules Composing the CMS Superconducting Coil.

[3] B. Blau et al., "The CMS conductor," IEEE Trans. Appl. Supercond., vol. 12, no. 1, pp. 345-348, March 2002.

[4] I. Horvath et al., "Manufacture of aluminum stabilized and reinforced superconductors by electron beam welding technique," in Proc. 15th Int. Conf. Magnet Technology, Beijing, 1988, pp. 1170-1173.

[5] R. Folch et al., "Continuous EB welding of the reinforcement of the CMS conductor," IEEE Trans. Appl. Supercond., vol. 12, no. 1, pp. 372-375, March 2002.

[6] J. Neuenschwander et al., Quality Monitoring of the Electron Beam Welding of the CMS Conductor Using Ultrasonics.

[7] A. Desirelli et al., "FE stress analysis of the CMS magnet coil," IEEE Trans. Appl. Supercond., vol. 10, no. 1, pp. 419-423, March 2000.

[8] S. S. Tavares et al., "Aluminum alloy production for the reinforcement of the CMS conductor," IEEE Trans. Appl. Supercond., vol. 12, no. 1, pp. 424-427, March 2002.

[9] B. Gallet et al., Conducteur aleph: interface cable supraconducteur-aluminum, Internal Report CEA/DAPNIA 5C2100T F-000 044 94.

[10] S. S. Tavares et al., "Mechanical characterization and assessment of the CMS conductor," IEEE Trans. Appl. Supercond., vol. 10, no. 1, pp. 399-402, March 2000.

[11] B. Seeber, L. Erbüke, R. Flükiger, I. Horvath, and J. Neuenschwander, "Variation of the residual resistivity ratio of the aluminum stabilizer for the compact muon solenoid (CMS) under dynamic stress," IEEE Trans. Appl. Supercond., vol. 10, no. 1, pp. 403-406, March 2000. 